\title{
The Innovative Business Model Canvas in the System of Effective Budgeting
}

\author{
Mikhail Nikolaevich Dudin ${ }^{1}$, Georgiy Nikolaevich Kutsuri ${ }^{2}$, Irina Jur'evna Fedorova ${ }^{2}$, Svetlana Sozrykoevna \\ Dzusova $^{2} \&$ Anzhela Zafitovna Namitulina $^{2}$ \\ ${ }^{1}$ Russian Academy of Entrepreneurship, Moscow, Russian Federation \\ ${ }^{2}$ Financial University under the Government of the Russian Federation, Moscow, Russian Federation \\ Correspondence: Mikhail Nikolaevich Dudin, Russian Academy of Entrepreneurship, Radio st. 14, Moscow, \\ 105005, Russian Federation.
}

Received: January 25, 2015 Accepted: February 6, 2015 Online Published: March 16, 2015

doi:10.5539/ass.v11n7p290 URL: http://dx.doi.org/10.5539/ass.v11n7p290

\begin{abstract}
This paper is aimed at studying the fundamentals for effective budgets on the basis of management concept called The Business Model Canvas. Management of the enterprise in modern conditions must be adaptive and oriented to the future. This allows not only to formulate a long-term development path, but also to solve a set of current and short-term functional aspects of the management. Among the main functional aspects that require attention, leading are aspects of cash management of the enterprise. Using the concept of management "business model canvas" allows the company to plan comprehensively their activities and its main financial results depending on the variability of the influence of external and internal factors, system modeling strength and direction of the effect of these factors as part of this management concept. This enables the company to not only increase the level of revenue and profits, but also to ensure the proper level of orientation on the client to maintain the competitiveness and sustainability of the business.
\end{abstract}

Keywords: The Business Model Canvas, sustained growth, budgeting, consolidated budget, financial strategy, financial management

\section{Introduction}

The establishment and development of any business requires making not only strategy but also The Business Model Canvas with its key or frame parameters which determine further sustained growth of an economic entity (Sabanti, 1998). The sustained growth of economic entities, including the financial aspect, should be considered as their ability to renew regularly their business models when accumulated positive qualities and development characteristics remain and evolve. That means environmental factors and conditions determine the sustained growth of enterprise (Dudin, 2013).

The finances of any economic entity are the basis of its successful work (McConnell, 2009; Geroski, 2004). At the same time, the stability of financial flows changes regularly or aperiodically. Thus we can suppose that tendencies towards the loss of sustained growth of an enterprise in external environment become localized exactly in ineffective financial management. Hence we can conclude that effective financial management is one of conditions for the sustained growth of an enterprise (Berry, 1980).

So, it is obvious that the sustained growth of economic entity is promoted, on the one hand, by effective financial management and, on the other hand, by enterprise's ability to accept and create changes and to bring them to the external environment (Grablowsky, 2000).

In this case, we speak about innovations in financial management (Aksyonov, 2010). Then the sustained growth will be based on a specific model of corporate management. This integral model will have variability, the priority of economic security and will avoid crises.

No doubt, it is impossible to avoid crises during the evolution of today's enterprises (Hamel, 1990), though enterprise's liability to development crises is caused by the ineffective work of all management subsystems. However both before, in traditional crisis management, and today, in modern preventive paradigm, they pay attention mainly at the financial aspect. Preventive management should be used to avoid crises in work and development (Barney, 1991). 
Preventive management is a set of preventive actions and measures (tactical and strategical) aimed at early detection of signals speaking well for local (systemic) problems in the work and development of an economic entity. Besides, these actions and measures are to eliminate these problems before the active stage of crisis begins. From the analytical and instrumental point of view, preventive measures check the peculiarities and specificities of how modern enterprises work and development.

Besides, preventive measures identify and use the reserves (potential including the financial one) of an economic entity to eliminate crisis and to preserve sustained development and balanced economic growth. So, the above allows stating that the sustained growth of an economic entity depends on the quality and effectiveness of financial management.

At that, financial flows are formed by the ability of an economic entity to create and sell a product in demand (Brushetal, 2010; Rumelt, 2003). However the consumer demand can change both spontaneously and predictably. Thus, from the viewpoint of strategic management, one of the most important conditions for the sustained growth of an economic entity is to foresee changes in consumer demand and to influence it. This, in its turn, guarantees relative stability in economic profit (operating income), i.e. it forms a prevailing incoming flow of money which covers expenses and contributes to profit. This indicates the effectiveness of financial management tools (particularly budgeting).

\section{Methods}

Methodologically, this paper is an adaptation of a theoretical and practical concept called The Business Model Canvas. It was developed by Alexander Osterwalder and Yves Pigneur for strategic business management in real economy (Osterwalder, 2010). The adaptation of The Business Model Canvas pursues a goal to increase the effectiveness of financial management in enterprises by optimizing management approaches to budget models. Besides, methodologically, this paper takes into account earlier progress in strategical and tactical business management, particularly such as:

- Building financial structures;

- Creating a map and hierarchy of business processes;

- Using balanced systems of indications;

- Using the concept of "thrifty production";

- Using the concept of "result-oriented budgeting".

The study of general theoretical, methodological and practical progress allowed developing an adapted version of The Business Model Canvas. It can be used by enterprises of real economy to increase the effectiveness of budget planning and to form consolidated budgets.

\section{Finding}

The strategic approach to financial management in modern economic entities is the fundamental one because bankroll determines all the rest of qualitative and quantitative characteristics of their sustained growth and systematic development. We can single out several basic aspects which determine the strategy and tactics of financial management in modern enterprises (Limitovskiy et al., 2012):

- Financial strategy is a functional strategy and should meet corporate or general strategy of growth and development;

- Financial strategy is based on internal and external analytical findings about possible changes and potential of an economic entity;

- From the viewpoint of formalization, a short-term financial strategy should include a set of budgets.

It should be noted that modern economic entities form a certain set of budgets which describe basic or operational activity and also investment and financial activities (Shakhovskaya, 2009), such as:

- Operating budget is formed by modeling the flows of impending receipts and expenditures caused by current business transactions for prospective budgeting period. The operating budget of an enterprise is based on the idea about financial cycle which mediates the work of an economic entity;

- Investment budget is first of all oriented at renewal by modernizing capital assets (fixed capitals forming a part of resource base). The investment budget of an enterprise is based on the idea about investment cycle which mediates the work of an economic entity;

- The financial budget of an enterprise systematizes and regulates the balance of earnings and money outflows. In fact, the development of financial budget means planning the floating funds and current engagements of an enterprise in the ratio necessary for financial stability during the budget period. 
As a rule, operating, investment and financial budgets are considered the first-level budgets. An enterprise can detail budget data for budgets of subordinate levels. The quantity of budget depends on the diversity of transactions and economic activities. The whole set of budgets is merged into one consolidated budget.

Consolidated budget (also called master budget) is an ordered plan of actions for an enterprise for some period of time (budgeting period). At that, consolidated budget contains target indices which characterize the forthcoming work and development period of this enterprise by its main business segments and areas of activities.

Traditional budgeting can be based on the financial structure of an enterprise or on the structurization of business processes. Budgeting based on financial structure presupposes the centers of financial responsibility including:

- The cost centre of financial responsibility. This is a functional subdivision of an enterprise responsible for drawing the budget of costs and expenditure. As a rule, cost centers include the industrial subdivisions and auxiliary services of an enterprise;

- The income centre of financial responsibility. This is a functional subdivision of an enterprise responsible for the budget of income. As a rule, income centers include the marketing service of an enterprise;

- The profit centre of financial responsibility. This is a functional subdivision of an enterprise responsible for profit formation. As a rule, profit centers include the accountant service of an enterprise;

- The investment centre of financial responsibility. This is a functional subdivision of an enterprise responsible for drawing investment funds. In modern enterprises, it is called a service of investment and development.

In its turn, budgeting based on the structurization of business processes accepts the premise that every business process has an inlet (in a form of incoming resources or results of previous processes) and an outlet. Consequently, business processes use resources, transform intermediate results into the end result and also form the budget of incomes, costs, profit and investment.

In our opinion, budgeting based both on financial structure and on the structurization of business processes should have a distinct strategic foundation in a form of the Business Model Canvas. The Business Model Canvas merging key elements in a single strategic field makes it possible, on the one hand, to study in details enterprise's work and, on the other hand, to analyze the flows of income, expenditure and profit influenced by the most important external factors which mediate internal environment changes.

\section{Discussion}

The Business Model Canvas is a modern tool for strategic management which can be used to optimize the financial aspect of activities run by an economic entity. The Business Model Canvas focuses on a value offered to customers. This value is made by transforming incoming resources into results (afterwards expressed in income). In basic exposition, The Business Model Canvas as a tool of strategic management, including financial management, contains nine basic units:

1) Value offered to customers;

2) Relations with suppliers;

3) Key resources ensuring enterprise's work and development;

4) Key business processes ensuring the transformation of resources into a result which determines value;

5) Target consumers;

6) Distribution channels for value offered to customers;

7) Relations with consumers (consumer-oriented approach);

8) Income from the consumed value;

9) Costs to create a value.

In this description, one can trace a basis on which the tools of The Business Model Canvas were created. This basis is a balanced system of indices. It was first described in the papers of David Norton and Robert Kaplan. It is common knowledge that the balanced system of indices proposed by Kaplan and Norton in 1992 (Kaplan, 2003) takes into account four key aspects in the work of today's companies: finances; consumers; business processes; training and development.

The essence of the balanced system of indices is to formulate financial strategy for an economic entity in several prospects, to set strategic goals and to measure the degree of goal reaching with the help of key effectiveness indices.

However the problem of the balanced system of indices is in that the development of economic entities is understood simplistically through the scope of unified hierarchy of business processes. Each stage of 
development may increase the number of business processes in an enterprise. Consequently, the number of key effectiveness indices will also grow (Stuart, 2000; Dudin, 2014).

It strongly impedes such management process as the analyses of enterprise activities and the detection of weak points in its work and development. Moreover (Limitovskiy, 2010; Ivashkovskaya, Z2009):

- Not all effectiveness indications can be expressed quantitatively in understandable and simply interpreted indices;

- Not for all business processes it is possible to find and fix the only correct and objective effectiveness index which can reflect accurately the specificity of a business process.

That is why we consider the tools used to build The Business Model Canvas another evolutional step in the theory and methodology of strategic management including the financial one. From the viewpoint of the theme, the key units of The Business Model Canvas can be structured the following way (see Figure 1).

We agree with the basic postulate of The Business Model Canvas that a value created for consumers should be in centre because the consumer-oriented approach is the dominant paradigm of modern corporate management (including the functional management of an enterprise).

At that, to create a value, it is necessary to have resources received from suppliers and directed into business processes. Interaction with suppliers and the inflow of resources for business processes determine the set of operational, investment and financial costs for an enterprise.

A value is created and offered to consumers for a purpose. Thus an economic entity should be oriented at the most full and the most optimal satisfaction of current and expected demand of target consumers. This can be achieved by using effective distribution channels and by constantly improved relations with consumers. This determines the income in operational, investment and financial activities.

The main receipts and expenditures form the consolidated budget of an enterprise. It can be detailed as the budget of profit and damage and also as an investment budget.

As it is said above, receipts and expenditures can be also structured on the basis of both company's financial structure and the hierarchy of business processes. In our opinion, in the majority of cases, it is optimal to use financial structure because the distribution of costs for business processes is more labour-intensive. Besides, one should bear in mind that the hierarchy of business processes used to structure receipts and expenditures in the consolidated budget of an enterprise require additional investments.

Additional investments are necessary to create the hierarchy of business processes and a map of these processes tied to the main functions or subdivisions of an enterprise.

Moreover, every business process should have its certificate (card) containing the most important information about:

- $\quad$ Process owner;

- Process inlets, outlets and suppliers;

- Process events, target and limitations;

- Process technologies, resources and risks;

- Process graphical description.

Obviously, it is not reasonable to build the hierarchy of business processes and to describe them for budgeting in case of an enterprise which uses functional but not business-process management approach. The business-process approach is useful only if the whole management of an enterprise is based on it.

It should be understood that organizational risks can arise when financial structure or business processes are used as a basis for budgeting. At a later date, these risks can influence the financial and economic indicators. Usually, mistakes and risks have the following reasons:

- Complex financial structures or business-process hierarchy are used in budgeting. This creates bureaucratic impediments. Besides, there is a high probability of information doubling. All this distorts final budget data;

- Functional or business-process structure of an enterprise is copied during the systematization of financial responsibility centers or processes which form income, costs and profit of an enterprise. Besides information doubling, here one can face the influence of "human factor". In this case every chief of financial responsibility centre and every owner of a business process will try to reduce the responsibility for income and effective expenditure;

- Temporary centers of financial responsibility or business processes cause ineffective expenditures and low income because the awareness of impermanence automatically reduces the responsibility of executors. 


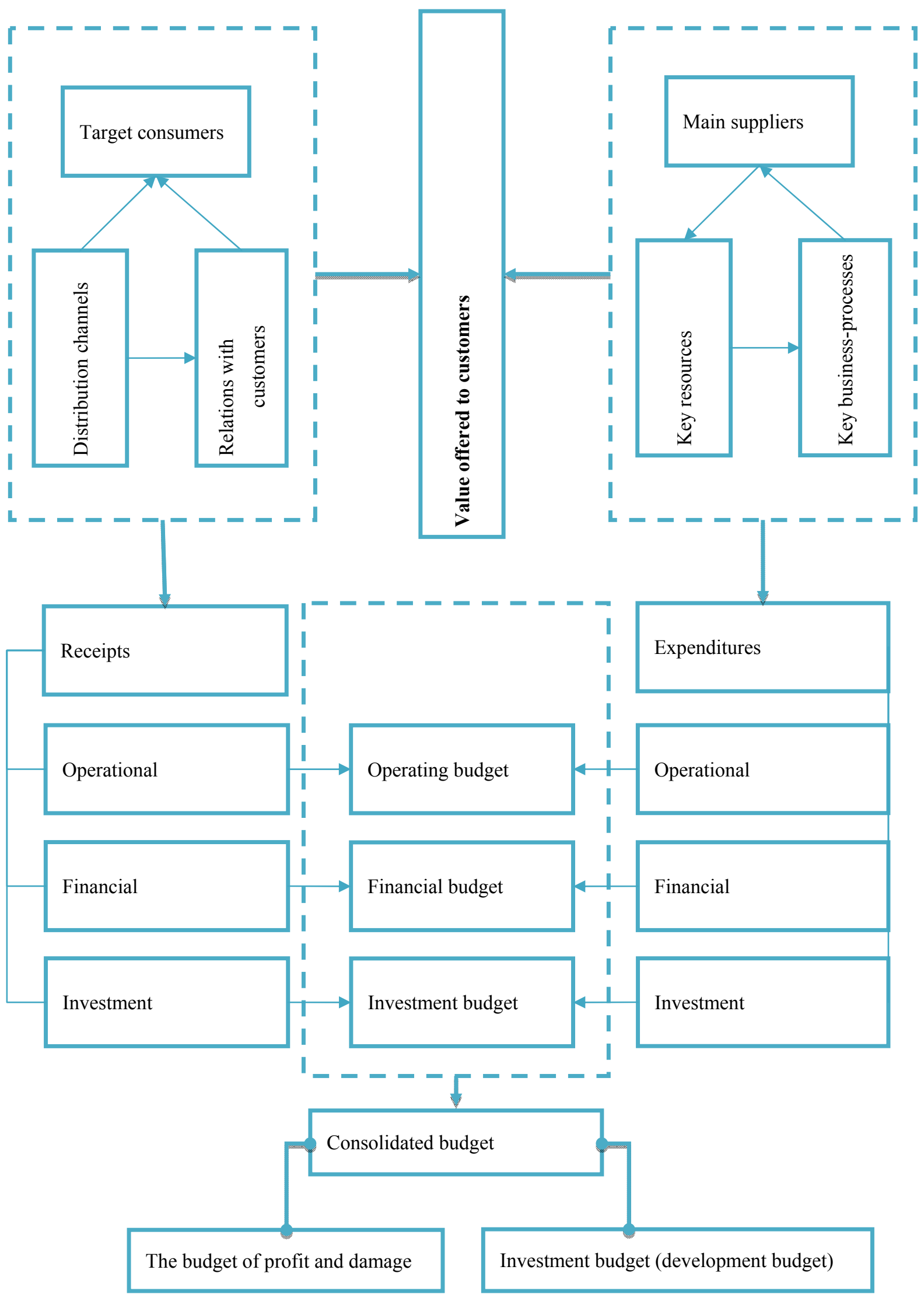

Figure 1. The Business Model Canvas in the system of effective budgeting for economic entities 
Above we presented not a complete list of possible organizational risks when using The Business Model Canvas for effective budgeting in economic entities. To avoid these and many other risks, the business model of an economic entity should be able to renew in strategic plane. The ideologists of The Business Model Canvas Osterwalder and Pigneur - (Clark et al., 2012) recommend creating not one but several alternative concepts of such canvas. This will allow foreseeing risks in work and development and the ways to minimize them. Effective budgeting based on The Business Model Canvas presupposes three types of budget. Every type of budget is based on a supposition about changes in demand for offered value:

- Basic consolidated budget. Consumer demand and the cost of the main resources used to create a value for consumers for a budget period remain conditionally invariable;

- Alternative budget (version 1). Consumer demand and the cost of the main resources used to create a value for consumers for a budget period can grow;

- Alternative budget (version 2). Consumer demand and the cost of the main resources used to create a value for consumers for a budget period can vary (for example, the demand can decline when the cost of resources rises).

In each alternative concept, it is reasonable to predetermine a list of necessary measures and actions to eliminate risks. It will allow making The Business Model Canvas a more flexible and adaptive tool for effective budgeting. So, The Business Model Canvas makes it possible:

- First: to detect ineffective and excessive costs in creating a value for consumers;

- Second: to detect lost economic profit in selling a value.

Consequently, The Business Model Canvas allows effective budgeting with a glance at current and forthcoming changes in external environment and consumer demand.

\section{Conclusions}

Financial management in economic entities and expected profit taking for the sustained growth of an enterprise depends on many factors. One of the most important factors of sustained work and development is the factor of demand. Today consumer demand is mediated by the real value of goods and services for consumers.

The target groups of consumers want the value offered by an enterprise to satisfy their need in full measure. That is why many enterprises invest their money in new unique offers for consumers. Expenses for new and knowledge-intensive products may be quite high but at the same time enterprise's income may remain at the same level. Thus effective budgets providing the sustained growth and development of economic entities are an urgent task.

Contemporary practice accumulated a wide range of solutions on effective budgeting within the framework of financial strategies for enterprises. However, in our opinion, it is optimal to use tools included in The Business Model Canvas for effective budgeting because of constant changes in external and internal environment. The Business Model Canvas helps to detect promptly the weak points in the intensity and rate of outgoing and incoming cash flows. Besides, it allows studying the external and internal space of activities for possible future transformations. Such systemic analytical basis contributes to objective relevant budgeting with a glance at current possible environmental changes. The paper describes the following findings:

- The sustained growth of enterprises is inter alia promoted by the effective financial management (it concerns cash flows: income, outcome and profit);

- The financial strategy of an enterprise should consider the whole set of external and internal environmental factors. The main attention should be paid at the harmonization of financial and corporate strategy for the development of an enterprise;

- In order to detail enterprise's financial strategy for a period ahead, it is optimal to present the development plans and lines in a consolidated budget decomposed into operating, investment and financial budgets;

- The Business Model Canvas allows an enterprise to identify the key needs of customers, and consequently to forecast potential gains (profit) and costs (expenses) required;

- The Business Model Canvas adapted for financial management presupposes three alternative concepts of consolidated budget and preventative steps aimed at decreasing risks if customer demand falls or the price for resources changes.

This paper considers general theoretical and methodological aspects of effective budgeting based on The Business Model Canvas. In future research papers, the authors plan to show the financial specificity of using The Business Model Canvas for budgeting in various areas and branches of real economic sector. 


\section{References}

Aksyonov, Ye. P. (2010). On the Essence of Functional Financial Management. The Review of the Tomsk State University, 3(11), 64-76.

Barney, J. (1991). Firm Resources and Sustained Competitive Advantage. Journal of Management, 17, 99-120. http://dx.doi.org/10.1177/014920639101700108

Berry, C. H. (1980). Corporate Growth and Diversification. Journal of Law \& Economics, 14(2), 371-384.

Brush, T. H., Bromiley, P., \& Hendrick, M. (2000). The Free Cash Flow Hypothesis for Sales Growth and Firm Performance. Strategic Management Journal, 21(4), 455-472.

Clark, T., Osterwalder, A., \& Pigneur, Y. (2012). Business Model You: A One-Page Method For Reinventing Your Career Paperback. John Wiley and Sons.

Dudin, M. N., Ljasnikov, N. V., Kuznecov, A. V., \& Fedorova, I. Ju. (2013). Innovative transformation and transformational potential of socio-economic systems. Middle East Journal of Scientific Research, 17(10), 1434-1437. http://dx.doi.org/10.5829/idosi.mejsr.2013.17.10.12313

Dudin, M. N., Prokof'ev, M. N., Fedorova, I. Ju., \& Frygin, A. V. (2014). The world experience of transformation of innovative approaches to assurance of financial stability of social economic systems. Life Science Journal, 11(9), 370-373.

Geroski, P., \& Gugler, K. (2004). Corporate growth convergence in Europe. Oxford Economic Papers, 56(4), 597-620. http://dx.doi.org/10.1093/oep/gpf055

Grablowsky, B. (2000). Management Hand Book. Management of the small Enterprise. Ways, problems, decisions.

Hamel, G., \& Prahalad, C. K. (1990). The Core Competence of the Corporation. Harvard Business Review.

Ivashkovskaya, I. V., \& Zhivotova, Ye. L. (2009). The Index of Growth Stability: The Empirical Testing in Russian Companies. The Review of the Saint-Petersburg University, 4(8), 3-29.

Kaplan, R., \& Norton, D. (2003). The Balanced Scorecard. Moscow, Olypm Business.

Limitovskiy, M. A. (2010). The Sustained Growth of a Company and Leverage Effects. Russian Management Journal, 2(8), 35-46.

Limitovskiy, M. A., Lobanova, N. Ye., Palamarchuk, V. P., \& Minasyan, V. B. (2012). Corporate Financial Management. Moscow, Yurait.

McConnell, C. R., \& Brue, S. L. (2009). Economics. Moscow: Infra-M.

Osterwalder, A., \& Pigneur, Y. (2010). Business Model Generation: A Handbook for Visionaries, Game Changers, and Challengers Paperback (p. 288). John Wiley and Sons.

Rumelt, R. P. (2003). What in the World Competitive Advantage? Policy Working Paper, 1, 25-34.

Sabanti, B. M. (1998). Theory of Finances (p. 168).

Shakhovskaya, L. S. (2009). Budgeting: Theory and Practice (p. 400). Moscow, Knorus.

Stuart, T. E. (2000). Interorganizational Alliances and the Performance of Firms: A Study of Growth and Innovation Rates in a High-Technology Industry. Strategic Management Journal, 21(8), 791-811.

\section{Copyrights}

Copyright for this article is retained by the author(s), with first publication rights granted to the journal.

This is an open-access article distributed under the terms and conditions of the Creative Commons Attribution license (http://creativecommons.org/licenses/by/3.0/). 